\title{
Assessment of Physicochemical Characteristics of Effluents from Paper Mill in the State of Uttar Pradesh, India
}

\author{
Singh Uma Shankar ${ }^{1}$, Panwar Suresh ${ }^{1}$, Jain R.K. ${ }^{1}$ and Tripathi Y.C. ${ }^{2 *}$ \\ 1. Central Pulp \& Paper Research Institute (CPPRI), Paper Mill Road, Himmat Nagar, Saharanpur-247001 (UP); \\ 2. Chemistry and Bioprospecting Division, Forest Research Institute (FRI), PO New Forest, Dehradun-248006 (Uttarakhand), \\ India;
}

\begin{abstract}
Discharge of large amount of wastewater as effluent from pulp and paper industries in the surrounding streams result in serious health and environmental problems. These large quantities of effluents need to be characterized for evolving proper treatment strategy prior to their disposal. Physicochemical characteristics of effluents from an agro-based paper mills located in Uttar Pradesh state of India were analyzed in terms of $\mathrm{pH}$, colour, TS, TDS, TSS, turbidity, BOD, COD, and AOX. The effluent samples collected from different processing unis of the paper mill varied considerably across the discharge streams. The mean values $\mathbf{p H}$, colour, TS, TDS, TSS, turbidity, BOD, COD, and AOX ranged from $1.82 \pm 0.03$ to $9.84 \pm 0.06$, 481.44 \pm 0.58 to $3936.16 \pm 5.76 \mathrm{PCU}, 1718.49 \pm 0.65$ to $4252.29 \pm 4.46$ ppm, 1518.27 \pm 2.65 to $3032.14 \pm 3.32 \mathrm{ppm}, 200.22 \pm 2.01$ to $1220.15 \pm 3.15 \mathrm{ppm}, 113.23 \pm 1.46$ to $481.22 \pm 2.61 \mathrm{NTU}, 355.65 \pm 3.50$ to $1342.22 \pm 3.50 \mathrm{ppm}, 881.52 \pm 3.19$ to $2710.12 \pm 4.52 \mathrm{ppm}$, and $15.75 \pm 0.51$ to $38.35 \pm 0.21 \mathrm{ppm}$ respectively. The results demonstrated markedly higher values of all physicochemical parameters of effluents from various processing units of the paper mill than the permissible limit thus necessitating appropriate treatment prior to their discharge in the environment.
\end{abstract}

Keywords: Paper mill, Effluents, Physicochemical characteristics, $\mathrm{BOD}, \mathrm{COD}$.

\section{INTRODUCTION}

Industrial discharges have been a major cause environmental pollution and hazardous contamination to soil and surface as well as ground water. Incessant discharge of toxic effluents to the adjoining crop fields and water bodies are reducing soil fertility and causing severe contamination to rivers, ponds, wells, canals, etc. thereby making the water unfit for irrigation and human consumption [1]. The pulp and paper industry is one of the major industries utilizing high quantity of water resulting in the generation of large amounts of wastewater [2]. It is the sixth largest environment polluting industry discharging a variety of pollutants into the environment [3].

The high consumption of fresh water and generation of a huge volume of toxic wastewater are the most important environmental concerns related to the pulp and paper industry. Even with the most modern and efficient operational techniques, about $60 \mathrm{~m}^{3}$ of water is required to produce a ton of paper, resulting in the generation of at least $50 \mathrm{~m}^{3}$ of wastewater [4]. The wastewater generated from paper making process include large number of degraded organic and inorganic contaminants, depending on types of raw materials, end product and use of chemicals such as sodium carbonate, sodium sulphide bisulfites elemental chlorine dioxide, calcium oxide, hydrochloric acid, etc [5]. The wastewater produced by pulp and paper mills contains more than 250 chemicals at different stages. Among the various processes of paper making, pulping especially chemical pulping and pulp bleaching generate highly contaminated wastewater which contains toxic substances such as resin acids, unsaturated fatty acids, diterpene alcohols, juvaniones, chlorinated resin acids and others. Major problems of the wastewaters are high organic content, dark brown colour, AOX and other toxic pollutants [6].

Most of Indian paper and pulp mills discharge their effluents, containing bleach and black liquor, directly into the receiving water bodies, and thus cause serious environmental concern [7,8]. The paper mill effluent contains high concentrations of recalcitrant dissolved organic matter, and when aquatic systems are overloaded it can induce high biochemical oxygen demand [9]. Unabated discharge of industrial effluents into the soil, sewage canals, rivers and other water bodies cause great damage to ecosystem and living biota.The wastewater discharged from the paper industry affect aquatic and land ecosystems [10]. Many research studies reported toxic effects on various fish species due to the exposure of pulp and paper industrial wastewater, including liver damage, mixed function oxygenase activity, physiological changes, respiratory stress, toxicity and lethal effects on the fish exposed to this wastewater [11-13]. Industrial effluents discharged in nearby water bodies produce alkalinity and salinity in irrigation water making it unfit for irrigation thus pose great challenge to the sustainability of irrigation agriculture [14]. Industrial effluents contaminate the land due to its high salt and metal contents and reduce soil fertility [15].

Pulp and paper mills effluent is complex in nature and its characteristics varies from mill to mill depending on numerous factors including type of raw materials, paper manufacturing process, washing, cooking, bleaching, etc. The extent of pollution due to discharge of wastewater from the pulp and paper factory to the receiving water body has been studied widely which confirmed that the effluents of the pulp and paper factory were loaded with several pollutants [16-23]. However, the volume and characteristics of the pollutants varied depending on the type of raw materials, manufacturing processes, amount of water and treatment technologies adopted [24]. Due to the severe toxic effects of pulp and paper mill effluents, reduction and/or removal of pollution load prior to their discharge into the environment is crucial. For 
efficient treatment of paper mill effluents, assessment of the actual pollution load exerted by each individual processing unit in terms of certain physicochemical parameters is considered essential. The present study therefore was aimed to determine the physicochemical characteristics of wastewater emanating from different processing units of an Indian pulp and paper mill located in Uttar Pradesh state of the country for devising efficient treatment strategy.

\section{MATERIALS AND METHODS}

chemicals used were of analytical grade and referred to Sd Fine Chem Ltd. and Ranbaxy. All the reagents and test solutions were prepared in triple distilled water and preserved in Schott Duran bottle. The laboratory glass used were washed with detergents and rinsed with distilled water and then oven dried at $200^{\circ} \mathrm{C}$ prior to use. The $\mathrm{pH}$ of the effluent samples was measured by using microprocessor based digital pH meter (Remi). The turbidity of effluent samples was measured by using turbidity meter and the readings were recorded as nephlometric turbidity unit (NTU).

\section{B. Selection of Paper Mill}

The pulp and paper mill selected for the study is located at $29^{\circ} 28^{\prime} 17.0292^{\prime \prime} \mathrm{N}, 77^{\circ} 41^{\prime} 48.2352^{\prime \prime} \mathrm{E}$ in the state of Uttar Pradesh (U.P.), India. This is a large scale agro-based paper mill primarily using wheat straw, bagasse and other agrowastes as raw material for manufacturing printing and writing papers with an installed capacity of 300 tpd. The mill adopts soda pulping process for pulp production using 10-12\% caustic $(\mathrm{NaOH})$ charge for wheat straw and $14-16 \%$ for bagasse during pulping. Oxygen bleaching followed by chemical bleaching is done in four stages following $\mathrm{CEHH}$ protocol and the total bleach chemical demand of the mill is 6-8\%. Each of the bleaching steps is preceded and followed by counter current washing with fresh water. The mill generates bleach plant effluent and combined effluent to the tune of $30-50 \mathrm{~m}^{3} / \mathrm{t}$ and $50-60 \mathrm{~m}^{3} / \mathrm{t}$ of paper respectively. For chemical recovery and effluent treatment, the mill uses conventional and activated sludge system.

\section{Collection of Sample}

Effluent samples were collected from different streams of the paper mill i.e. chlorination $(\mathrm{C})$, extraction $(\mathrm{E})$, combined bleach plant (CBP) and Combined effluent (CE) at an interval of one hour for six hours and then mixed to make it composite for physicochemical analysis. The effluent samples were collected in pre-cleaned plastic containers in summer (May, 2015) and winter (January, 2016) to observe any change in the characteristics of the effluent but not much variation was observed due to change in temperature (season), since the process conditions in the paper making remains almost consistent. Furthermore, the samples were acidified with nitric acid and containers with samples were preserved in refrigerator at $4^{0} \mathrm{C}$ till further analysis. Any change in the characteristics of the effluent mainly depends on the raw material and the chemical used in pulping and bleaching process.

\section{Physicochemical Characterization of Effluents}

Effluents samples collected from all the four streams of processing units of the paper mill were analyzed for their physicochemical characteristics following prescribed standard protocols [25-27]. The $\mathrm{pH}$ of effluent samples was measured at the site of collection using microprocessor based $\mathrm{pH}$ meter (Labtronics). Colour of the samples was analyzed by spectrophotometric method. Turbidity of the effluent was measured by using turbidity meter (Hach 2100AN). The remaining effluent characteristics parameter, i.e., total solid (TS), total dissolved solid (TDS), total suspended solid (TSS), biological oxygen demand (BOD) and chemical oxygen demand (COD) were determined volumetrically/titrimetrically as per standard methods. The adsorbable organic halide (AOX) was measured with AOX analyzer (Analytic JenaMulti X2000). All tests and measurements were carried out in triplicates to access the repeatability of the results.

\section{RESULTS AND DISCUSSION \\ A. Physicochemical Characteristics of Effluents}

The agro-based paper mill under study produces a variety of writing and printing paper using bagasse, wheat straw, and other agricultural residue as a primary raw material. The effluent samples collected from various processing units of the mill were subjected to physicochemical characterization for parameters such as $\mathrm{pH}$, colour, TS, TDS, TSS, turbidity, BOD, COD, and AOX as per standard methods. The mean values and standard deviation of studied physicochemical parameters of the paper mill effluents are presented in Table1.

Table 1: Physicochemical values of effluents from different processing stages of the paper mill

\begin{tabular}{|c|c|c|c|c|}
\hline \multirow{2}{*}{ Parameters } & \multicolumn{4}{|c|}{ Processing stages of the paper mill } \\
\hline & $\mathbf{C}$ & $\mathbf{E}$ & CBE & $\mathbf{C E}$ \\
\hline $\mathrm{pH}$ & $1.82 \pm 0.03$ & $9.32 \pm 0.04$ & $7.26 \pm 0.07$ & $9.84 \pm 0.06$ \\
\hline $\begin{array}{l}\text { Colour } \\
\text { (PCU) }\end{array}$ & $481.44 \pm 0.58$ & $2230.25 \pm 0.98$ & $921.50 \pm 0.07$ & $3936.16 \pm 5.76$ \\
\hline TS (ppm) & $1718.49 \pm 0.65$ & $2435.20 \pm 5.18$ & $2084.67 \pm 3.15$ & $4252.29 \pm 4.46$ \\
\hline TDS (ppm) & $1518.27 \pm 2.65$ & $2218.66 \pm 2.64$ & $1704.32 \pm 5.35$ & $3032.14 \pm 3.32$ \\
\hline TSS (ppm) & $200.22 \pm 2.01$ & $217.54 \pm 2.63$ & $380.35 \pm 3.20$ & $1220.15 \pm 3.15$ \\
\hline $\begin{array}{l}\text { Turbidity } \\
\text { (NTU) }\end{array}$ & $121.22 \pm 2.62$ & $149.22 \pm 1.75$ & $113.23 \pm 1.46$ & $481.22 \pm 2.61$ \\
\hline BOD (ppm) & $404.55 \pm 1.65$ & $571.54 \pm 3.50$ & $355.65 \pm 3.50$ & $1342.22 \pm 3.50$ \\
\hline COD (ppm) & $881.52 \pm 3.19$ & $1162.25 \pm 5.26$ & $921.52 \pm 5.76$ & $2710.12 \pm 4.52$ \\
\hline $\mathrm{AOX}(\mathrm{ppm})$ & $35.84 \pm 0.12$ & $38.35 \pm 0.21$ & $24.25 \pm 1.14$ & $15.75 \pm 0.51$ \\
\hline
\end{tabular}

Values are given as Mean $\pm S E(n=3)$

It is evident from the results of physicochemical analysis of effluents from different processing units presented in Table 1 that the values of all the studied parameters vary considerably across the various processing units of the paper mill. 


\section{(i) Measurement of $\mathrm{pH}$}

The mean value of $\mathrm{pH}$ varied from $1.82 \pm 0.03$ to $9.84 \pm 0.06$ across the four processing stages which may be due to the use of different process and chemicals at various different processing units. The $\mathrm{pH}$ value is a measure of acidity and alkalinity of effluents which is useful in designing treatment protocol and determining its efficiency. Effluent from different processing units may have both acidic and alkaline nature. In this study, effluent from chlorination section showed minimum mean value of $\mathrm{pH}$ which is in highly acidic range due to the formation of organic acids while processing. In fact, reactions of chlorine with water at chlorination stage lead to formation of hypochlorous acid and hydrochloric acid. The low pH of C-stage effluents may be due to dissociation of hypochlorous acid into hydrogen ion and hypochlorite ion. The highest $\mathrm{pH}$ value of effluents from $\mathrm{CE}$ unit may be due to the addition of alkali at this stage for the precipitation of total solids which produces hydroxyl ions in water thereby raising the $\mathrm{pH}$ of effluent making it alkaline in nature [28]. The effluent from $\mathrm{CE}$ unit recorded the $\mathrm{pH}$ value of 9.84 which is a little higher than WHO prescribed tolerance limit of $\mathrm{pH}$ value i.e. 6 to 9 for the paper industry effluent [29]. The discharge of waste water into water bodies may cause a drop or increase in their $\mathrm{pH}$ due to the size and activities of microbial population. The $\mathrm{pH}$ of water is the important for the biotic compound because most of the plant and animal species can survive between narrow $\mathrm{pH}$ from slightly acidic to slightly alkaline.

\section{(ii) Measurement of Colour}

Colour of effluents or wastewaters depend on concentration of lignin which come up due to the presence of low and high molecular weight chlorinated organic compound produced during different processing stages like pulping, bleaching and alkali extraction as the lignin degradation products [30,31]. The colour of the effluent from all the four processing stages measured in PCU showed considerable variation ranging from $481.44 \pm 0.58$ to $3936.16 \pm 5.76 \mathrm{PCU}$. Visibly, the effluent had a yellowish brown to dark brown appearance at the time of samples collection. Data presented in table 1 revealed that $\mathrm{CE}$ effluent exhibited highest colour value followed by $\mathrm{E}$ and $\mathrm{CBP}$ stages. The darkest colour of CE effluent of the paper mill may be due to presence of some amount of black liquor. The colour of effluent has impact on its aesthetics, transparency and gas solubility [32].

\section{(iii) Determination of $\mathrm{TS}$}

The mean total solids (TS) concentrations in effluents from $\mathrm{C}, \mathrm{E}, \mathrm{CBE}$ and $\mathrm{CE}$ units ranged from $1718.49 \pm 0.65$ to $4252.29 \pm 4.46 \mathrm{ppm}$ (Table 1). Effluent discharge at $\mathrm{CE}$ unit showed the highest TS whereas the lowest TS were found in effluent at the $\mathrm{C}$ unit (Fig. 1). The observed values of TDS after the factory effluent discharge were higher than the WHO maximum permissible limit of 500 ppm for disposal into surface water bodies [33]. Disposal of wastewater with high TS in water bodies may adversely affect the aquatic flora through delaying their photosynthetic process due to lesser clarity and consequent reduction in the passage of light. Furthermore, such effluents get warmed rapidly and hold more heat which is unfavourable for aquatic lives that are adapted to survive at a lower temperature.

\section{(iv) Determination of TDS}

Total dissolved solid (TDS) is a measure of the combined sum of inorganic and organic substances contained in a liquid which primarily includes minerals, salts, and organic matter which can be a general indicator of water quality. In the present study, the highest TDS was found in effluent samples from CE unit (3032.14 $\pm 3.32 \mathrm{ppm})$ followed by $\mathrm{E}(2218.66 \pm 2.64 \mathrm{ppm})$ and $\mathrm{CBE}(1704.32 \pm 5.35 \mathrm{ppm})$ units. Effluents from $\mathrm{C}$ unit however recorded the lowest (1518.27 $\pm 2.65 \mathrm{ppm}$ ) TDS (Fig.1). It is obvious that TDS values in discharge from all the processing units are higher than the WHO maximum permissible limit of 500 ppm (500 $\mathrm{mg} / \mathrm{L}$ ) for the disposal of wastewater into surface water [33]. Increased concentrations of dissolved solids can also have technical effects. Discharge of wastewater with higher TDS in water bodies may increase salinity of water thereby making it unfit for irrigation and drinking purposes. Consumption of water with high TDS are reported to cause detrimental impact on alimentary canal, respiratory system, nervous system, coronary system besides, causing miscarriage and cancer [34].

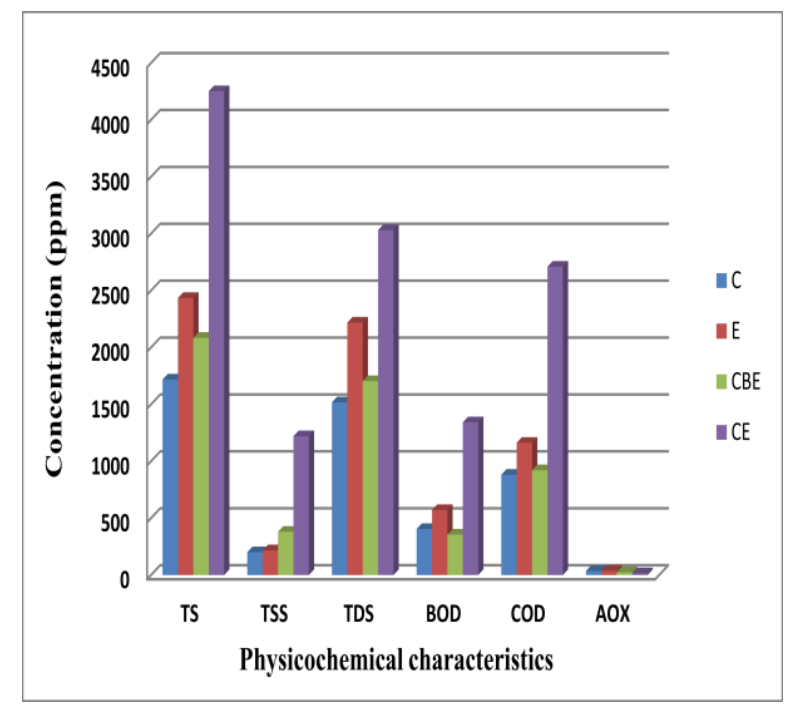

Fig.1: Physicochemical values of effluents from different streams of paper mill

\section{(v) Determination of TSS}

The undissolved matters including fibres, inorganic fillers, pigments, etc. in the effluents signify their total suspended solids (TSS). The mean TSS contents of effluents from C, E, CBE and CE units varied from 200.22 \pm 2.01 to $1220.15 \pm 3.15 \mathrm{ppm}$. Effluents from CE unit showed the highest value of TSS followed by CBE and E units; C unit effluents however recorded the lowest TSS (Fig. 1). The values of TSS in effluents from all the four streams found to be higher than the WHO maximum limit of 100 ppm (100 $\mathrm{mg} / \mathrm{L}$ ) for discharge of waste water to surface water bodies. Suspended solids reduce the rate of photosynthesis by aquatic flora, oppress benthic organism, and retard the efficiency of biological treatment processes [35]. 


\section{(vi) Determination of Turbidity}

As an important characteristic, turbidity of effluent is due to the presence of insoluble matters, soluble coloured compounds, and plankton which is measured either as a reduction in the intensity of transmitted light or as an increase in the intensity of scattered light. Effluents from C, E, CBE and $\mathrm{CE}$ units exhibited mean value of turbidity as $121.22 \pm 2.62,149.22 \pm 1.75,113.23 \pm 1.46$ and $481.22 \pm 2.61$ NTU respectively. Highest turbidity was observed for effluents from CE unit whereas $C$ unit effluents showed the lowest turbidity (Table 1). The turbidity values of effluents from all the four units are in consonance with respective TS, TDS and TSS values. Higher turbidity retards light penetration in the water thereby reducing photosynthesis and production of dissolved oxygen. Effluent turbidity can be considered as efficiency measure of coagulation-flocculation process of the unit. The results of turbidity measurement evidently suggest much higher turbidity in effluents of all processing units and the values are greater than the WHO prescribed standard limits of 5 NTU (ideally below 1 NTU ) [33].

\section{(vii) Determination of $\mathrm{BOD}$}

The amount of oxygen required for microbial degradation of organic matter as well as the self purification capacity of the water body is termed as biological oxygen demand (BOD). It is a measure of the organic pollution load of effluents thus quantifies the dissolved oxygen levels. The mean values of BOD for effluents at $\mathrm{C}, \mathrm{E}, \mathrm{CBE}$ and $\mathrm{CE}$ units ranged from $355.65 \pm 3.50$ to $1342.22 \pm 3.50 \mathrm{ppm}$. Effluent from $\mathrm{CE}$ unit recorded the highest value of BOD while $\mathrm{CBE}$ unit effluent showed the lowest value (Fig. 1). Effluents from the all the units exhibited BOD values much higher than prescribed limit of $100 \mathrm{ppm}(100 \mathrm{mg} / \mathrm{l})$ for safe disposal of effluents as per Indian Standard (IS). The high biological oxygen demand and coupled low oxygen content of effluents affect the survival of aquatic animals of receiving water body [36].

\section{(viii) Determination of COD}

The amount of oxygen required to breakdown both organic and inorganic matter is termed as chemical oxygen demand (COD) which is one of important indicators of pollution load in effluents. The mean value of COD for effluents from all the four units recorded in the range of $881.52 \pm 3.19$ to $2710.12 \pm 4.52 \mathrm{ppm}$. Highest value of COD was found for the effluent from $\mathrm{CE}$ unit whereas minimum COD value was recorded for $\mathrm{C}$ unit effluents (Fig. 1). The COD values of effluents from all the four processing units are higher than $350 \mathrm{mg} / \mathrm{l}$, the acceptable limits [37]. This suggested the toxic nature of effluents which may be due to high chemical concentration along with biologically resistant organic substances [38].

\section{(ix) Determination of $\mathrm{AOX}$}

The bleaching sections of paper mills, generally use chlorine-based chemicals which result in release of organically bound chlorine compounds such as dioxins and furans, chlorinated phenolic compounds, etc. in the effluents discharged from these units. The adsorbable organic halide (AOX) is the measure of such organically bound chlorine compounds [39]. As per the results (Table 1), the mean values of AOX in effluents from the four processing units ranged from $15.75 \pm 0.51$ to $38.35 \pm 0.21 \mathrm{ppm}$. Effluents from $\mathrm{E}$ unit recorded the maximum AOX value followed by those discharged from $\mathrm{C}$ and $\mathrm{CBE}$ units. The $\mathrm{CE}$ unit effluents however showed the lowest AOX value (Fig. 1). Discharge of wastewater with high concentration of harmful organically bound chlorine compounds into the environment has enough potential to disrupt the structure and functioning of the natural ecosystem. Some of these chemicals are toxic, mutagenic, persistent, bio-accumulating thus exerting acute toxic effect on aquatic organisms, cause severe ecological threats and numerous harmful disturbances in biological system [40].

The physicochemical analysis revealed the extent of pollution load in effluent discharge from different processing units of the paper mill. Data presented in table 1 amply pointed towards highest pollution load in the effluents discharged from $\mathrm{CE}$ unit as compared to those from $\mathrm{C}, \mathrm{E}$ and CBE units. Effluent discharge from $\mathrm{CE}$ unit contain bleach plant effluent, surplus backwater from paper machine and discharge from entire processing units which are responsible for its darkest colour, higher BOD, COD along with higher TS, TDS, TSS and turbidity as well. Colour in effluent of CE unit is mainly due to lignin, its derivatives and polymerized tannins which are mostly discharged from the pulping, bleaching and recovery sections. Nevertheless, presence of low and high molecular weight chlorinated organic compounds generated during pulping and pulp bleaching may also be responsible for colour of effluents from different processing units of the mill. The higher level of colour in the bleach effluent of CE unit is indicative of high lignin content extracted out with alkali. Higher COD in CE effluents is due to presence of highly non-biodegradable lignin, phenol compounds and various toxic substances $[41,42]$. Results also indicate that the effluent from E-unit is more polluted than that of from $\mathrm{C}$ and $\mathrm{CBE}$ units owing to high TS, TDS, BOD and COD. Effluents from various processing units exhibited physicochemical values higher than permissible limits thus need to be properly treatment for their safe disposal $[43,44]$.

\section{CONCLUSION}

Pulp and paper mill contribute to pollution because of production of high quantity of waste water during the manufacturing of paper. The physicochemical characterization of the paper mill effluents indicated that the values of most of the studied parameters are very much higher than the prescribed limits set by regulatory bodies for discharge of waste water in agricultural fields and water bodies. However, $\mathrm{pH}$ of the effluents from all processing units is found well within the acceptable limit whereas other parameters exhibited much higher values than the permissible limits for their safe disposal. Hence proper strategies should be used to treat the effluents prior to its disposal to the environment. In this context, a combination of physical, chemical, and biological treatments under optimal treatment conditions may provide a long-term solution. Nevertheless, optimization of whole operational practices including raw material, by-product recovery, best use/reuse of water, reduction in wastewater generation and better maintenance of 
the machinery are also important apart from treatment and other pollution control measures.

\section{ACKNOWLEDGEMENT}

Authors are grateful to the Director, CPPRI, Saharanpur, UP and the Director, Forest Research Institute Dehradun for providing necessary analytical facilities. Help and cooperation rendered by paper mill personnel towards collection of effluent samples and relevant technical information and production statistics of the mill is thankfully acknowledged.

CONFLICT OF INTEREST: None declared.

\section{REFERENCES}

[1] Chhonkar P.K., Datta S.P., Joshi H.C. and Pathak H., Impact of industrial effluents on soil health and agriculture-Indian experience: Pat-1, distillery and paper mill effluents, Journal of Scientific \& Industrial Research, 59, 350-361 (2000)

[2] Razali M., Ahmad Z., Ahmad M. and Ariffin A., Treatment of pulp and paper mill wastewater with various molecular weight of polyDADMAC induced flocculation, Chemical Engineering Journal, 166, 529-535 (2011).

[3] Savant D., Abdulrahman R. and Ranade D., Anaerobic degradation of adsorbable organic halides (AOX) from pulp and paper industry wastewater, Bioresource Technology, 97, 1092-1104 (2006).

[4] Thompson G., Swain J., Kay, M. and Forster C.F., The treatment of pulp and paper mill effluent: a review, Bioresource Technology, $\mathbf{7 7}$ 275-286 (2001).

[5] Ali M. and Sreekrishnan T., Aquatic toxicity from pulp and paper mill effluents: A review, Advances in Environment Research, 5, 175 196 (2001).

[6] Yedla S., Mitra A. and Bandyopadhyay M., Purification of pulp and paper mill effluent using Eichornia crassipes, Environmental Technology, 23, 453-465 (2002)

[7] Tripathi, G. and Tripathi. Y.C., Current status of environmental pollution in India, Industry, Environment and Pollution (A. Kuma and P.K. Goel eds.), ABD Publisher, Jaipur, pp. 317-343 (2000).

[8] Afzal M., Shabir G., Hussain I. and Khalid Z.M., Paper and board mill effluent treatment with the combined biological-coagulationfiltration pilot scale reactor, Bioresource Technology, 99, 7383-7387 (2008).

[9] Pizano-Torres R.I., Roach K.A. and Winemiller K.O., Response of the fish assemblage to a saltwater barrier and paper mill effluent in the Lower Neches River (Texas) during drought, Journal of Freshwater Ecology, 32, 147-162 (2017).

[10] Singh U.S. and Tripathi Y.C., Impact of paper industries on biodiversity and environment, International Biodiversity Congress (IBC 2018), October 4-6, 2018, Forest Research Institute (FRI), Dehradun, India (2018)

[11] Munkittrick K.R., Servos M.R., Carey J.H. and Van Der Kraak G.J. Environmental impacts of pulp and paper wastewater: evidence for a reduction in environmental effects at North American pulp mills since 1992, Water Science \& Technology, 35, 329-338 (1997).

[12] Tripathi Y.C., Tripathi G. and Verma P. Chemical toxicity and health hazards, Modern Trends in Environmental Biology (G. Tripathi ed.), CBS Publishers and Distributors, New Delhi, pp. 265 280 (2002).

[13] Schnell A., Hodson P.V., Steel P., Melcer H. and Carey J.H., Enhanced biological treatment of bleached Kraft mill effluents: II Reduction of mixed function oxygenase (MFO) induction in fish, Water Research, 34, 501-509 (2000).

[14] Medhi U.J., Talukdar A.K. and Deka. S., Impact of paper mil effluent on growth and development of certain agricultural crops, Journal of Environmental Biology, 32, 185-188 (2011).

[15] Kumar A., Tripathi Y.C., Singh Sushma, and Tripathi G., Meta pollutants in living environment: Threats and challenges, Dimensions of Environmental Threats (A. Kumar ed.), Daya Publishing House, New Delhi, pp. 1-20 (2003).

[16] Akhan J.C., Physicochemical determination of pollutants in waste water and vegetable samples along the Jakara wastewater Channelin Kano Metropolis, Kano State, Nigeria, European Journal Scientific Research, 23, 122-123 (2008).
[17] Devi N.L, Yadav I.C, Shihua Q.I, Singh S, and Belagali S.L. Physicochemical characteristics of paper industry effluents - A case study of South India Paper Mill (SIPM), Environmental Monitoring and Assessment, 177, 23-33 (2011).

[18] Kuzhali S.S., Manikandan N. and Kumuthakalavalli R., Physicochemical and biological parameters of paper industry effluent, Journal of Natural Product and Plant Resources, 2, 445-448 (2012).

[19] Shakirat K.T. and Akinpelu A.T., Study of heavy metals pollution and physicochemical assessment of water quality of River Owo, Agbara, Nigeria. International Journal of Water Resources and Environmental Engineering, 5, 434-341 (2013).

[20] Sharma A. and Ramotra A., Physico-chemical analysis of paper industry effluents in Jammu city (J\&K), International Journal of Scientific and Research Publications, 4, 1-4 (2014).

[21] Bhatnagar, A. Assessment of physico-chemical characteristics of paper industry effluents, Rasayan Journal of Chemistry, 8, 143-145 (2015)

[22] Muhamadi K.O.L., Kirabira J.B., Byaruhanga J.K., Godiyal R.D. and Kumar A., Characterization and evaluation of pulp and paper from selected Ugandan grasses for paper Industry, Cellulose Chemistry and Technology, 50, 275-284 (2016).

[23] Jebessa Z.F. and Wondemagegnehu E.B., Physicochemical characterization of Upper Awash River of Ethiopia polluted by Anmol Product Paper Factory, International Journal of Water and Wastewater Treatment, 4, dx.doi.org/10.16966/2381-5299.154 (2018).

[24] Lenntech B.V., Pulp and paper industry water treatment, Netherlands, (2011). https://www.lenntech.com/pulp-and-paperindustry-water-treatment.htm

[25] American Public Health Association (APHA), Standard Methods for the Examination of Water and Wastewater $\left(21^{\text {st }}\right.$ ed.), Baltimore, Maryland, USA: Port City Press, 25-80 (2005).

[26] Canadian Pulp and paper Association (CPPA), Technical Section Standard Test Method, H5, Montreal, 20-23 (1993).

[27] Maheshwari R., Rani B., Saxena A., Prasad M. and Singh U., Analysis of effluents released from recycled paper industry, Journal of Advanced Scientific Research, 3, 82-85 (2012).

[28] Deepali, KK., Gangwar, R and Joshi, BD. Comparative study of physico-chemical properties of effluent from tannery industries, Indian Journal of Environmental Sciences, 3, 49-50 (2009).

[29] Kirkpatric, N., Pulp and Paper Industries, Pollution Prevention and Abatement Handbook, World Bank Group, 395-399 (1998).

[30] Bajpai, P. and Bajpai, P.K., Mini review: Biological colour removal of pulp and paper mill wastewaters, Journal of Biotechnology, 33, 211-220 (1994).

[31] Nagarathnamma, R., Bajpai, P. and Bajpai, P.K. Studies on decolorization, degradation and detoxification of chlorinated lignin compounds in kraft bleaching effluents by Ceriporiopsis subvermispora, Process Biochemistry, 34, 939-948 (1999)

[32] Yuxing,W and Jain,Y. Decolourisation of synthetic dyes and waste waters from textile, Water Research, 33, 3512-3520 (1999).

[33] World Health Organization (WHO), Guidelines for Surface water quality, Volume 1, Geneva (2008).

[34] Reddy, P.M. and Subba Rao, N., Effects of industrial effluents on the ground water regime in Vishakapatnam, Pollution Research, 20 383-386 (2001).

[35] Sdguide.org., Environmental Guide for Pulp and Paper Production. European Paper Merchants Association (EUGROPA), http://www.eugropa.com/downloads/Eugropa $\% 20$ Guide\%20Pulp\%20\&\%20Paper.pdf. (2008) assessed on $15^{\text {th }}$ April, 2020.

[36] Saravana Sundaram E.J., Elayaperumal R., Kiruthika M., Ramya V. and Dharmalingam P., Effluents of paper mill: Physico-chemical properties of water, International Journal of ChemTech Research, $\mathbf{6}$, 3541-3545 (2014).

[37] Yusuff R.O. and Sonobare A.J., Characterisation of textile Industries effluents in Kaduna, Nigeria and pollution implications, Global Nest the International Journal, 6, 211-220 (2004).

[38] Dutta S.K., Study of the physicochemical properties of effluent of the paper mill that affected the paddy plants, Journal of Environment Pollution, 5, 13-19 (1999).

[39] Jamil, T.S., Ghaly, M.Y., El-Seesy, I.E., Souays, E.R. and Nasr, R.A., A comparative study among different photochemical oxidation 
processes to enhance the biodegradability of paper mill wastewater, Journal of Hazardous Materials, 185, 353-358 (2011)

[40] Vidyarthi K., Dutt D. and Upadhyaya J.S., Reduction of pollutants in paper mill effluents by aquatic plants, Cellulose Chemistry and Technology, 45, 291-296 (2011).

[41] Pandey, S., Parvez, S., Sayeed, I., Haque, R., Hafeez, B.B. and Raisuddin, S., Biomarkers of oxidative stress: A comparative study of river Yamuna fish Wallago Attu, Science of the Total Environment, 309, 105-115 (2003).

[42] Chandra, R. and Singh, H., Chemical decolourization of anaerobically treated distillery effluent, Indian Journal of Environment Protection, 19, 833-837 (1999).

[43] Singh, R.S., Marwaha, S.S. and Khanna, P.K., Characteristics of pulp and paper mill effluents, Journal of Industrial Pollution Control, 12, 163-172 (1996).

[44] Bajpai P and Bajpai, P.K. Reduction of organochlorine compounds in bleach plant effluents. Advances in Biochemical Engineering/Biotechnology, 57, 213-259 (1997). 